Neurosurg Focus 20 (3):E11, 2006

\title{
Simple closure following transsphenoidal surgery
}

\author{
Technical note
}

\author{
William T. Couldwell, M.D., Ph.D., Peter Kan, M.D., and Martin H. Weiss, M.D. \\ Department of Neurosurgery, University of Utah School of Medicine, Salt Lake City, Utah; and \\ Department of Neurosurgery, Keck School of Medicine, University of Southern California, \\ Los Angeles, California
}

\begin{abstract}
$\checkmark$ The most common nonendocrine complication after transsphenoidal surgery is cerebrospinal fluid (CSF) leak. Many neurosurgeons have advocated the routine reconstruction of the floor of the sella turcica using autologous fat, muscle, fascia, and either cartilage or bone after transsphenoidal surgery to prevent postoperative CSF fistulas. However, the use of autologous grafting requires a second incision, prolongs operative time, and adds to the patient's postoperative discomfort. In addition, the presence of sellar packing may interfere with the interpretation of postoperative images. To avoid these disadvantages, the authors suggest that routine sellar reconstruction or closure after transsphenoidal surgery is unnecessary unless an intraoperative CSF leak is encountered. The incidence of postoperative CSF leakage in the patients reported on in this series is no higher than that reported by others, and no other complications such as pneumatocele have been encountered in approximately 2700 patients in whom no intraoperative CSF leak was encountered. The authors conclude that routine closure of the floor of the sella turcica or sphenoid is unnecessary in the absence of intraoperative CSF leak.
\end{abstract}

KEY WORDS • cerebrospinal fluid leak • transsphenoidal surgery • pituitary surgery

$\mathrm{T}$ RANSSPHENOIDAL surgery is the standard approach for the treatment of sellar lesions because of its high success rate and low rate of morbidity and mortality. The main nonendocrine postoperative complication with this approach is CSF leak. ${ }^{2,5}$ Hardy and McCutcheon ${ }^{10}$ described the use of autologous fascia, muscle, and fat, supported by a piece of nasal cartilage, for the closure and reconstruction of the sella turcica. Many neurosurgeons have continued to use autologous fascia, muscle, and fat as well as various synthetic materials for routine closure or reconstruction of the sella turcica with the aim of preventing postoperative CSF leakage.

The use of autologous grafting requires a separate incision, prolongs operative time, and causes additional discomfort to the patient. Furthermore, the presence of packing materials, either autologous or synthetic, in the sella turcica may interfere with the interpretation of postoperative images, and certain synthetic materials can even elicit a host reaction or infection. To avoid these disadvantages, we propose that routine closure or reconstruction of the sella turcica is unnecessary after transsphenoidal surg-

Abbreviation used in this paper: CSF = cerebrospinal fluid. ery unless an intraoperative CSF leak is encountered. In our experience, this practice has not led to an increased incidence of CSF leak, sellar pneumatocele, or empty sella syndrome.

\section{Surgical Technique}

A standard endonasal or sublabial approach is performed as described previously.,15 The sellar floor is removed using a series of up- and down-biting rongeurs. Following this removal, the dura mater is cauterized and opened in a cruciate fashion with a No. 11 blade. After adequate removal of the tumor, the integrity of the arachnoid membrane is tested thoroughly using visual inspection to check for CSF leakage and a Valsalva maneuver or bilateral venous occlusion to raise intracranial pressure. In cases of microadenoma or a small macroadenoma with no evidence of CSF leak, no formal attempt at closure is made, and a single layer of Surgicel is placed over the arachnoid layer and the remaining pituitary gland for hemostasis. The nasal or sublabial self-retaining retractor is then removed. When using a purely unilateral endonasal approach, the authors take steps to ensure that the middle turbinate and the quadrangular cartilage are brought back 
W. T. Couldwell, P. Kan, and M. H. Weiss

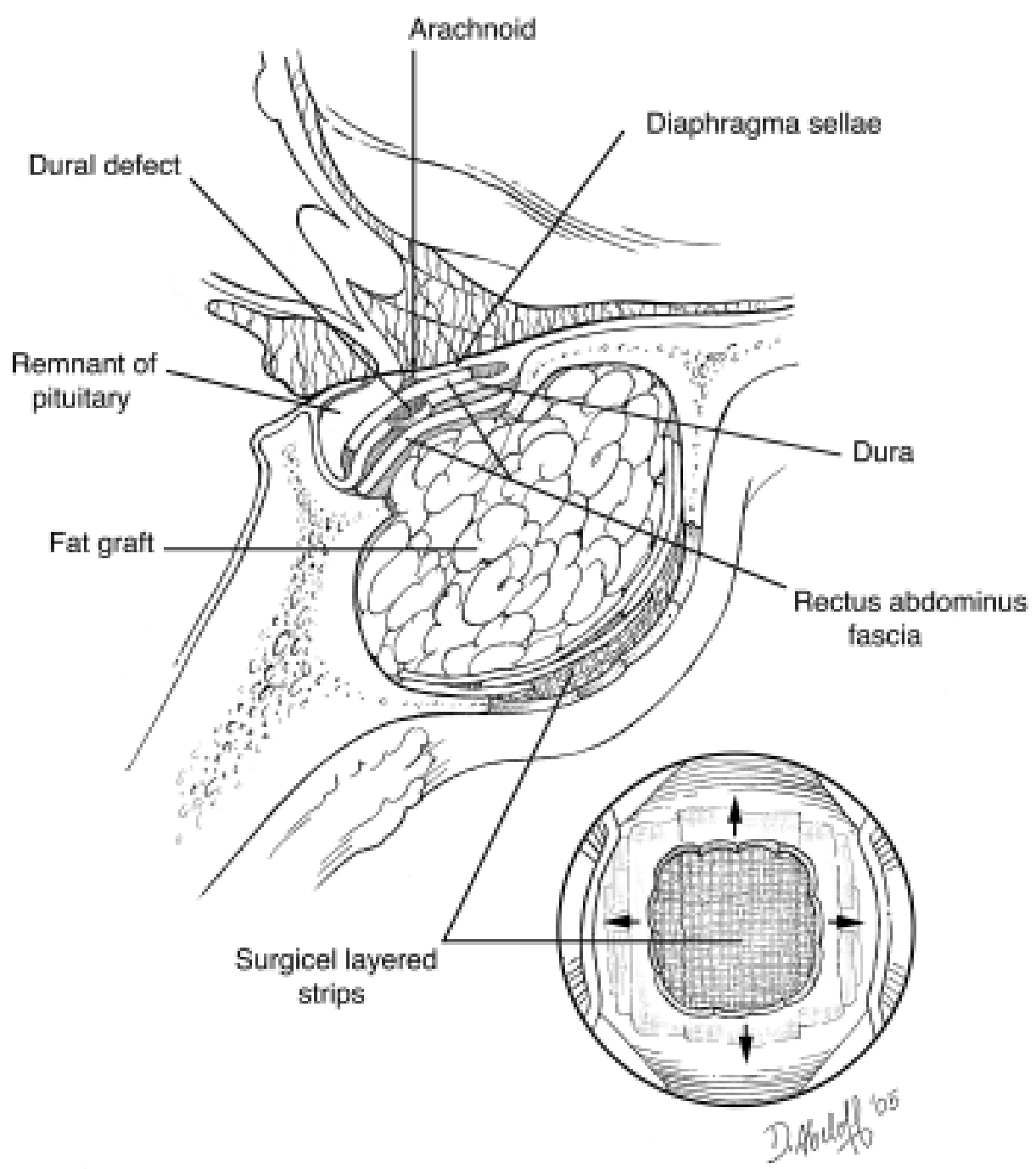

FIG. 1. Closure in cases with intraoperative CSF leak. The dural defect is covered with fascia and the sphenoid is packed with fat to buttress the fascial graft. The fat is held in place in the sphenoid with a sling of Surgicel strips placed in a lattice pattern.

into their normal positions at the end of the procedure. For the sublabial approach, the septum is reduced to its midline, and nasal tampons are placed as described previously. A transseptal endonasal approach is closed as previously described. ${ }^{15}$

In patients with an obvious CSF leak, the following closure is performed. Autologous fat (with or without fascia) is harvested, usually from the lower abdomen or, alternatively, the lateral thigh. For a small CSF leak, a fat graft alone is inserted in the sphenoid sinus and held in place as described later. For a more copious CSF leak with a larger opening in the arachnoid, rectus abdominus fascia or fascia lata is harvested and positioned within and over the dural defect and buttressed in place with a fat graft in the sphenoid sinus. In both cases, the fat graft is held in the sphenoid with a sling of Surgicel gauze placed over the opening, with the ends of the gauze wedged beneath the margins of the lateral, inferior, and superior lips of the sphenoid face (Fig. 1). This is a crucial maneuver, in that the Surgicel gauze must be adequately positioned to ensure that the fat graft remains in place. A Valsalva maneuver is performed after grafting to assess the integrity of the graft. When an extended transsphenoidal approach is performed, we use lumbar drainage, in most cases for a period of 3 to 4 days postoperatively. ${ }^{6}$

\section{Results}

In a combined series of more than 4200 transsphenoidal surgeries performed by the senior authors (M.H.W. and W.T.C.), approximately two thirds $(\sim 2700)$ of the procedures were performed without reconstruction of the sellar floor. In these patients without an intraoperative CSF leak, no additional complications of late CSF leak, infection, or pneumatocele were noted.

The simple closure technique using fascia and fat was performed in the remainder of surgical cases. In the early part of the series, we used a small piece of Marlex mesh (Bard, Cranston, RI) fashioned so that it could be wedged within the sphenoid opening to hold the fat in place. More 
recently, in the past 500 cases, we have used the aforedescribed Surgicel sling technique. In these latter 500 cases, there was one CSF leak $(0.2 \%)$; this patient required a repeated operation to repack the sphenoid sinus. It is our practice to immediately return the patient to the operating room for repacking in the face of a postoperative CSF leak. ${ }^{6}$

Our routine is to perform magnetic resonance imaging in all patients annually for 7 years postoperatively. If no tumor is found, an additional image is obtained at 10 years. The simple closure techniques described here have been used since 1981, with a median follow up of 12 years.

\section{Discussion}

Various techniques of sellar reconstruction and closure have been described in the literature. Most surgeons use autologous tissues such as muscle, fat, and fascia, $5,8,10,18,19$ whereas a few use synthetic materials, including a combination of Gelfoam and collagen fleece, ${ }^{4}$ Vicryl patches, ${ }^{17}$ and polyester-silicone dural substitute, ${ }^{3}$ to fill or close the sella turcica after tumor removal. The use of autologous grafting usually necessitates a separate incision, prolongs operative time, causes additional discomfort to the patient, and produces abdominal and thigh scars that can be cosmetically unappealing. On the other hand, although an additional incision can be avoided by using synthetic material, these foreign bodies may cause a host reaction, serve as a nidus for infection, or complicate postoperative imaging.

Various materials have been used to hold the sellar packing in place, including cartilage and bone, ${ }^{10}$ alumina ceramic, ${ }^{14}$ silicone, ${ }^{11}$ stainless steel, ${ }^{9}$ titanium, ${ }^{1}$ MacroSorb (MacroPore, San Diego, CA), ${ }^{12}$ polytetrafluoroethylene, ${ }^{13}$ porous polyethylene,${ }^{16}$ and fibrin glue ${ }^{17}$ The routine use of these materials presents its own set of disadvantages. Compatibility with and artifacts seen on magnetic resonance imaging were reported with stainless steel and titanium,,${ }^{1,9}$ and the possibility of host-tissue reaction was associated with silicone. ${ }^{11}$

To avoid these problems, the senior authors do not routinely close or reconstruct the sella turcica after transsphenoidal surgery unless an intraoperative CSF leak is encountered. We have not experienced an increased incidence of CSF leak or symptomatic empty sella syndrome in our practice. In patients with an intraoperative CSF leak, we reconstruct the floor of the sella with autologous fascia and fat grafting. The use of fat or fat and fascia provides an autologous material that does not interfere with postoperative imaging.

\section{References}

1. Arita K, Kurisu K, Tominaga A, et al: Size-adjustable titanium plate for reconstruction of the sella turcica. Technical note. J Neurosurg 91:1055-1057, 1999

2. Black PM, Zervas NT, Candia GL: Incidence and management of complications of transsphenoidal operation for pituitary adenomas. Neurosurgery 20:920-924, 1987
3. Cappabianca P, Cavallo LM, Mariniello G, et al: Easy sellar reconstruction in endoscopic endonasal transsphenoidal surgery with polyester-silicone dural substitute and fibrin glue: technical note. Neurosurgery 49:473-476, 2001

4. Cappabianca P, Cavallo LM, Valente V, et al: Sellar repair with fibrin sealant and collagen fleece after endoscopic endonasal transsphenoidal surgery. Surg Neurol 62:227-233, 2004

5. Ciric I, Ragin A, Baumgartner C, et al: Complications of transsphenoidal surgery: results of a national survey, review of the literature, and personal experience. Neurosurgery 40: 225-237, 1997

6. Couldwell WT: Transsphenoidal and transcranial surgery for pituitary adenomas. J Neurooncol 69:237-256, 2004

7. Couldwell WT, Weiss MH: Transnasal transsphenoidal approach, in Apuzzo MLJ (ed): Surgery of the Third Ventricle, ed 2. Baltimore: Williams \& Wilkins, 1998, pp 553-574

8. Faria MA Jr, Tindall GT: Transsphenoidal microsurgery for prolactin-secreting pituitary adenomas. Results of 100 women with the amenorrhea-galactorrhea syndrome. J Neurosurg 56: 33-43, 1982

9. Freidberg SR, Hybels RL, Bohigian RK: Closure of cerebrospinal fluid leakage after transsphenoidal surgery: technical note. Neurosurgery 35:159-160, 1994

10. Hardy J, McCutcheon IE: Pituitary microadenomas, in Apuzzo MLJ (ed): Brain Surgery: Complication Avoidance and Management. New York: Churchill Livingstone, 1993, Vol 1, pp 271-295

11. Kabuto M, Kubota T, Kobayashi H, et al: Long-term evaluation of reconstruction of the sellar floor with a silicone plate in transsphenoidal surgery. J Neurosurg 88:949-953, 1998

12. Kaptain GJ, Vincent DA, Laws ER Jr: Cranial base reconstruction after transsphenoidal surgery with bioabsorbable implants. Neurosurgery 48:232-234, 2001

13. Kitano M, Taneda M: Subdural patch graft technique for watertight closure of large dural defects in extended transsphenoidal surgery. Neurosurgery 54:653-661, 2004

14. Kobayashi S, Sugita K, Matsuo K, et al: Reconstruction of the sellar floor during transsphenoidal operations using alumina ceramic. Surg Neurol 15:196-197, 1981

15. Liu JK, Orlandi RR, Apfelbaum RI, et al: Novel closure technique for the endonasal transsphenoidal approach. Technical note. J Neurosurg 100:161-164, 2004

16. Park J, Guthikonda M: The Medpor ${ }^{\mathrm{TM}}$ sheet as a sellar buttress after endonasal transsphenoidal surgery: technical note. Surg Neurol 61:488-493, 2004

17. Seiler RW, Mariani L: Sellar reconstruction with resorbable vicryl patches, gelatin foam, and fibrin glue in transsphenoidal surgery: a 10-year experience with 376 patients. J Neurosurg 93:762-765, 2000

18. Tindall GT, Collins WF Jr, Kirchner JA: Unilateral septal technique for transsphenoidal microsurgical approach to the sella turcica. Technical note. J Neurosurg 49:138-142, 1978

19. Wilson CB, Dempsey LC: Transsphenoidal microsurgical removal of 250 pituitary adenomas. J Neurosurg 48:13-22, 1978

Manuscript received January 5, 2006.

Accepted in final form February 15, 2006.

Address reprint requests to: William T. Couldwell, M.D., Ph.D., Department of Neurosurgery, Suite 3B409, 30 North 1900 East, Salt Lake City, Utah 84132. email: william.couldwell@hsc.utah.edu. 